\title{
Laboreal
}

Volume $6 \mathrm{~N}^{\circ} 2$ | 2010

Varia

\section{Caminhos para a articulação entre linguagem, ergologia, trabalho e desenvolvimento}

Caminos para la articulación entre lenguaje, ergologia, trabajo y desarrollo

Parcours pour l'articulation entre langage, ergologie, travail et développement

Pathways to the links between language, ergology, work and development

Cecília Souza-e-Silva e Vera Lucia Sant'Anna

\section{(2) OpenEdition}

Journals

Edição electrónica

URL: http://journals.openedition.org/laboreal/8894

ISSN: 1646-5237

Editora

Universidade do Porto

Refêrencia eletrónica

Cecília Souza-e-Silva e Vera Lucia Sant'Anna, « Caminhos para a articulação entre linguagem, ergologia, trabalho e desenvolvimento », Laboreal [Online], Volume 6 №2 | 2010, posto online no dia 01 dezembro 2010, consultado o 10 outubro 2019. URL : http://journals.openedition.org/laboreal/8894

Este documento foi criado de forma automática no dia 10 outubro 2019.

Laboreal está licenciado com uma Licença Creative Commons - Atribuição-NãoComercial 4.0 Internacional. 


\title{
Caminhos para a articulação entre linguagem, ergologia, trabalho e desenvolvimento
}

\author{
Caminos para la articulación entre lenguaje, ergologia, trabajo y desarrollo \\ Parcours pour l'articulation entre langage, ergologie, travail et développement \\ Pathways to the links between language, ergology, work and development
}

Cecília Souza-e-Silva e Vera Lucia Sant'Anna

\section{REFERÊNCIA}

Artigo original : Souza-e-Silva, M.C.P. \& Sant'Anna, V. (2010) Parcours pour

l'articulation entre langage, ergologie, travail et developpement. Ergologia, n. 4 , pp. 105-120.

\section{Pensar o desenvolvimento}

Durante muito tempo, pensava-se que a questão do desenvolvimento estivesse na mão de um grupo de economistas, que acreditavam que o sucesso de suas políticas seria alcançado a partir de construtos matemáticos e de objetos quantificáveis (horas trabalhadas, toneladas de aço produzidas, quilômetros quadrados de florestas destruídas etc). Hoje em dia, várias correntes de pesquisa estão em busca de outros apoios. Certos economistas, como Amartya Sen (2000), consideram que a riqueza medida pelo Produto Interno Bruto (PIB) não representa uma referência satisfatória e agregam ao Índice de Desenvolvimento Humano (IDH) outros elementos - o acesso à educação, a esperança de vida ao nascer, as taxas de alfabetização de adultos. Propõem avaliar o desenvolvimento como o processo de ampliação das possibilidades de ação dos indivíduos. A atenção concentra-se na expansão das "capabilidades" das pessoas (noção central na obra do autor - uma fusão entre capacidade e liberdade) em agir de acordo 
com seus valores. "Essas capabilidades podem ser aumentadas pelas políticas públicas, mas, por outro lado, as capabilidades participativas do povo também podem influenciar o direcionamento a ser dado pelas políticas públicas" (2000, p.32). A avaliação do desenvolvimento de uma sociedade deve levar em conta, primordialmente, as liberdades das quais seus membros desfrutam.

2 Do ponto de vista da linguagem, a promoção do desenvolvimento de diferentes formas de "letramento", que permitem aumentar as "capabilidades" do indivíduo, vêm ampliar as proposições de Amartya Sen. Sabe-se que não há iletrados definitivos, mas pessoas que podem sair dessa situação de diferentes maneiras, independentemente de sua idade, em função de suas atitudes, sua situação, da formação que lhes é proposta, da maneira pela qual o meio reconhece e valoriza a aquisição de suas novas competências.

3 Sabemos, ainda, segundo as palavras de Schwartz, Adriano e Abderrahmane, que "não se pode (...) tratar dos problemas de desenvolvimento sem prestar atenção renovada ao que chamamos de atividade de trabalho" (2008, p.11). A ergologia se propõe a dar maior visibilidade àquilo que se realiza nessa atividade, o que exige que o desenvolvimento incorpore a cultura produzida pelo coletivo humano, de tal maneira que essa produção possa ser reconhecida como parte das normas organizadoras do processo de desenvolvimento previsto pelas políticas locais e globais. Integrar as renormalizações no trabalho como parte do acervo cultural de um grupo constitui, igualmente, uma das formas de aumentar as "capabilidades" do homem no mundo e, portanto, de promover o desenvolvimento. Assim, a concepção de desenvolvimento como liberdade, que consiste em reforçar ou aumentar as capacidades dos indivíduos de uma sociedade, tal como formulada por Amartya Sen, é compatível com os esforços dos estudos ergológicos em trazer à tona o que efetivamente se concretiza na atividade de trabalho. Pensar em "capabilidade", isto é, no binômio liberdades/capacidades implica também a relação linguagem/ergologia. Esta relação não dissocia as capacidades de seu contexto sócio-histórico: ao contrário, preocupa-se em ancorá-las fortemente nas microdecisões que intervêm nas situações mais gerais.

\section{Convergências entre ergologia e estudos da linguagem}

Estabelecemos convergências entre três princípios ergológicos e os estudos da linguagem [1]. o primeiro, consiste em afirmar que "a abordagem do desenvolvimento deve ter em conta a complexidade da vida humana e a exigência de associar desenvolvimento às necessidades", isto é, o desenvolvimento (...) deve ser universal, plural e multidimensional. Segundo esse princípio, os estudos discursivos exigem um entendimento particular do que seja linguagem e seu ensino. Uma das condições para que se tenha êxito é que esse ensino se sistematize numa escola universalizada e se afaste da compreensão de língua como sistema, como representação do real, como instrumento de informação.

5 É importante também pensar a língua e seu ensino a partir das possibilidades que têm as pessoas de expandir suas competências discursivas. Essa visão é plural na sua essência, porque só existe articulada a aspectos históricos e sociais de uma determinada comunidade. E essa comunidade, para estar apta a desenvolver suas "capabilidades" de compreensão do mundo, precisa reconhecer as exigências que a multidimensionalidade das situações vividas exige. 
6 No que concerne ao segundo princípio, isto é, a "necessidade de uma abordagem dialética entre o local e o global ou singular e universal, a fim de desenvolver a capacidade de análise das coletividades humanas", referimo-nos aos estudos que procuram compreender o local e o singular, para, a partir daí, chegar a afirmações mais gerais.

70 terceiro princípio trata do "necessário debate a ser promovido sobre as relações entre apropriação pelos povos de aspectos científicos e tecnológicos e o questionamento das ajudas por meio de inovações sem transferência de tecnologia (...) os projetos precisam incorporar as condições, os meios e a gestão das atividades humanas, de modo a valorizar experiência, saberes e potencialidades locais". Para participar dessa discussão, podemos afirmar que existe uma análise do discurso do Brasil que constrói sua própria história e apresenta contribuições ao corpo conceitual dessa área.

\section{Que papel tem a linguagem na ampliação das "capabilidades" dos indivíduos?}

8 Diante da proposta de avaliar "capabilidades" que significam liberdade, e, portanto, têm impacto no desenvolvimento, afirmamos que o letramento possibilita liberdade de decisão e de participação na vida em sociedade. Sabemos que a privação, ainda que relativa, de conhecimento da linguagem pode resultar em privação de "capabilidades". Mas em que consiste o letramento ? Pode-se defini-lo como um conjunto de práticas que utilizam a escrita em contextos e fins específicos. Os especialistas não pressupõem efeitos universais do letramento, mas efeitos ligados às práticas sociais e culturais dos diferentes grupos que utilizam a escrita, notadamente, na atividade de trabalho, objeto desta discussão (BENTOLILA, 1996 ; GEFFROY, 2002 ; KLEIMAN, 1995 ; SOARES, 2003).

9 As "capabilidades" relacionadas ao letramento são fundamentais para a valorização do trabalhador. Aumentar a capacidade de letramento melhora sua auto-estima, reforça a referência com o grupo ao qual pertence, e reflete-se de forma profunda nas liberdades e nas escolhas do grupo para o desenvolvimento social e econômico.

10 Para aprofundar a questão do letramento e para avançar outras etapas, propomos aquilo que chamamos "letramento discursivo" que, segundo os pressupostos da análise do discurso, assinala o processo de ruptura com a concepção de sentido como expressão de idéias de um autor sobre as coisas. Ao contrário, considera-se que "a língua é polissêmica e opaca (...), o sujeito diz sempre mais, menos ou outra coisa em relação ao que queria dizer (em virtude dos efeitos da ideologia, do inconsciente) e as condições de produção carregam ingredientes contraditórios" (POSSENTI, 2004, p. 360). Além disso, a análise do discurso propõe que a língua tem uma ordem própria, mas essa ordem é posta a funcionar segundo o processo discursivo delimitado por certa conjuntura. Portanto, o sentido não é da ordem da língua, antes decorre dos posicionamentos discursivos que por sua vez são de ordem sócio-histórica. Assim, embora a língua seja a mesma para diversos enunciadores, o sentido do que dizem pode não sê-lo porque isso decorre de fatores que não são da ordem da língua. $O$ mesmo enunciado pode ter sentidos diferentes se pertencerem a posicionamentos discursivos diferentes (MAINGUENEAU, 2008).

11 Pode-se dizer que a análise do discurso nasceu como resposta à questão : como ler ? Nesse sentido, ela se apresenta como uma teoria que trata das coerções que atuam sobre o discurso. Tal perspectiva, quando aplicada a estudos sobre o trabalho 
(NOUROUDINE, 2002), pode favorecer também nosso desenvolvimento como pesquisadores porque ela permite levar em conta, além dos discursos em situação de trabalho stricto sensu, os discursos que circulam em outros espaços, sobretudo na mídia.

\section{Um exemplo de análise segundo a perspectiva discursiva}

12 Com o propósito de apontar possibilidades oferecidas pela análise do discurso, apresentamos caminhos de análise, tomando como ponto de referência sentidos atribuíveis ao termo "competência", palavra-chave do universo do trabalho. Os resultados dessa análise nos trazem uma compreensão mais ampla dos espaços de produção de discursos que (re)definem o que é trabalho.

13 Recorremos a dois objetos, aparentemente sem relação entre si, mas cujo funcionamento discursivo os aproxima porque impõem normas para se comportar no mundo em geral e no trabalho em particular [2] :

14 (1) o manual de instruções para a preparação de novos empregados de uma empresa de hotelaria, portanto, ligado de forma direta a uma situação de trabalho específica [3];

15 (2) as matérias veiculadas na revista Você S/A [ ${ }^{4}$, publicada pela Editora Abril, voltadas aos temas emprego e empregabilidade, portanto, não relacionada a uma situação de trabalho stricto sensu. A aproximação entre esses dois objetos tem como propósito mostrar que os discursos relacionados a situações de trabalho e aqueles que não circulam nos lugares tradicionais das normas do trabalho partilham um mesmo espaço discursivo $\left.{ }^{5}\right]$ e realimentam-se mutuamente.

\subsection{0 guia de atividades e atitudes do profissional da empresa hoteleira}

Este guia é um manual de instruções e tem como pretensão que o trabalhador do hotel siga certos padrões de comportamento profissional. Analisamos fragmentos que permitiram depreender sentido(s) de competência que circulam no campo das normas sobre o trabalho. Identificamos processos de referência e modos de ação por meio de marcas que indicam determinado posicionamento por parte do enunciador :

17 (1) itens lexicais, tais como, "atividade", "procedimento", "comportamento", "serviço", associados à idéia de padrão de qualidade ;

(2) modalidades enunciativas : deônticas e avaliativas ;

(3) definições e exemplificações ;

(4) tempos verbais e pessoas do discurso.

21 O importante não é apenas o emprego de determinadas formas, mas, principalmente, os procedimentos discursivos nos quais essas formas se engajam.

Depreende-se pela análise que a excelência no trabalho representa o alcance do padrão de qualidade, resultado da repetição dos procedimentos, daquilo que foi apresentado no treinamento. Reforçam-se as normas, apaga-se a experiência anterior e o já vivido, estabelecendo-se o que vem a ser competência, que coincide com a idéia de padrão de qualidade - "É fazer nossa atividade com o menor número de falhas possíveis e sempre da mesma forma". Além disso, por meio de processo injuntivo, que neste manual se 
concretiza tanto pela modalidade deôntica - "deve estar envolvido, deve ser sempre repetido" - quanto pela avaliativa - "Muito bem! Agora você já é um profissional que sabe o que a Empresa espera de você e como pode realizar um serviço com Padrão de Qualidade" -, o enunciador normaliza a ação ao expressar um saber que leva o interlocutor a aderir a esse discurso. A injunção suscita o dizer e, também, o fazer ; não é reversível, emana daquele que se encontra em posição de aconselhar/ordenar. Ao que recebe a dica/ conselho/ordem resta concordar (dizer) e necessariamente executar (fazer). Tem-se, portanto, uma competência adquirida por meio da repetição dos mesmos procedimentos sem falhas, supondo "uma racionalidade inerente ao processo de produção, como se este fosse dotado de leis naturais a que os homens e sua ciência devessem subordinar-se e obedecer" (SENNET, 2006).

Também por meio das pessoas do discurso - neste caso, o você genérico - e, ainda, das modalidades deônticas, o texto incita a uma ação de vigilância mútua e denuncismo entre os trabalhadores e, ao mesmo tempo, de comprometimento com a chefia. "Cabe a você a iniciativa de estar atento a possíveis falhas de outros que possam lhe prejudicar. (...) Se a reclamação envolve algum colega de trabalho, não tente esconder isso do seu chefe, achando que está protegendo o colega, pois você poderá contribuir para agravar o fato". Apagam-se, assim, as formas de articulação e os laços de solidariedade entre os trabalhadores. A competência vai sendo definida pela capacidade do trabalhador se afastar do seu coletivo, protegendo sua individualidade, em nome do emprego e do bom nome da empresa. Apaga-se também uma possível história de vida no trabalho, apagam-se sentimentos de continuidade e, portanto, de interpretação sobre o que um eventual coletivo poderia ter vivido.

\subsection{O guia de comportamento no trabalho na revista VOCÊ S/A}

Neste guia, a idéia de competência como a capacidade de se adaptar rapidamente a novas exigências, marca dos novos tempos no trabalho, aparece em vários textos que estabelecem uma relação entre homens e mulheres apresentados como destemidos instituídos pela revista como enunciadores - e os leitores, co-enunciadores, interpelados a se identificar com esse modelo. Itens lexicais como "rapidez", " velocidade", "dinamismo", "hábito", "sucesso", "fracasso", "autonomia" indicam posicionamento desse enunciador, marcas que perpassam relatos, conselhos, dicas, partes de um conjunto de traços de didaticidade (MOIRAND, S ; BRASQUET-LOUBEYR, M. , 1994). Esses itens expõem de modo pedagógico as demandas do mercado de trabalho. Isto é, o que se deve ou não fazer e os riscos de não se seguirem essas soft laws, aquelas normas que prescrevem mais para dissuadir do que para reprimir. A presença de tais traços, no caso da mídia, aponta para uma estratégia para passar da ordem da informação - objetivo primeiro e declarado - à ordem da definição de normas.

São várias as marcas lingüísticas que identificam traços de didaticidade, entre elas a exemplificação, a explicação, a enumeração, as perguntas retóricas, as generalizações, as formas impessoais etc. Trata-se, então, de uma interpenetração de conhecimentos : como se dá a passagem entre "quem sabe", o enunciador instituído pela revista, e o interlocutor-leitor presumido? O que se quer fazer compreender para além da informação?

O vocabulário de especialistas de recursos humanos e os depoimentos de profissionais sobre o perfil ideal de trabalhadores orientam os sentidos de um determinado modo de 
agir: "sair da zona de conforto, vencer a resistência, aprender e adaptar-se rapidamente a situações novas, tornar-se mais flexível e versátil, ter iniciativa, usar o tempo livre para vencer desafios no trabalho". Essas características definem um trabalhador interpelado a tomar em suas mãos o seu destino e o da instituição : "Faça as malas. Como fazer a mudança dar certo. Faça mais e melhor. Ela nunca se acomodou". Busca-se, assim, garantir a adesão a determinados comportamentos.

Ao reforçar as atitudes que o mercado espera dos profissionais nas novas relações de trabalho, a revista marca uma característica dos meios de comunicação como formadores de crenças, de culturas e de valores: valoriza-se a ação do indivíduo, portanto prescrevem-se comportamentos e, por meio da busca da concordância das pessoas, procura-se dar sentido de participação à sua subordinação. Se o que importa é o "coeficiente pessoal de engajamento", desqualifica-se o antigo papel do coletivo, visto como resistente a mudanças.

Além dos relatos de profissionais e especialistas, há uma grande quantidade de dicas na revista, em vários formatos, muitas vezes em forma de listas, dedicadas à circulação de temas muito diferentes, tais como "saúde", "amizade", "finanças", "carreira", "etiqueta" . Trata-se de um processo de didatização que tem por objetivo provocar a adesão mais imediata desse tipo de público. Uma lista é sempre um elemento facilitador, tanto do ponto de vista da compreensão quanto da memória. Os relatos, as dicas, não constituem injunções emitidas pela hierarquia responsável pelo trabalho, mas se impregnam de um caráter de autoridade a partir do momento em que o leitor da revista se coloca na posição de um profissional que busca receber tais conselhos.

Percebe-se, portanto, que as normas descendentes vindas da hierarquia, como no manual de instruções, não são suficientes para se compreender os sentidos de trabalho. A mídia atribui-se também esse espaço gerador de normas, procedimentos, a serem seguidos em busca do sucesso. Ao enunciar os conselhos na forma de generalizações, por meio do presente atemporal, a fonte da fala citada não é o indivíduo, mas uma classe de enunciadores - "Todas as negociações gozam de uma anatomia comum; Em qualquer condição, o melhor passo inicial é enviar uma mensagem clara, simples e positiva" - e o co-enunciador, interpelado como você genérico, não indica um leitor específico, mas um conjunto de leitores privilegiados - "Fazendo isso, você tem grandes chances de assumir ; você evita o desperdício de recursos como tempo e dinheiro".

30 Esse sistema enunciativo estruturado por coenunciadores genéricos e presente atemporal tem como resultado um disfarce da injunção : atribui-se a qualquer situação vivida e a qualquer pessoa que dela participe os contornos prescritos para a ação, não há distância entre o que se aconselha e o que se executa, apaga-se o investimento do trabalhador na sua atividade e ignora-se a variabilidade do meio. Ainda que não se trate de normas oficiais, pode-se perceber que esses conselhos/dicas passam a constituir normas sobre o modo de pensar. Estamos, então, no campo do caráter normativo dos conceitos, dos saberes instituídos (SCHWARTZ, 1997). A possibilidade de conceituar determinados objetos, de colocar em circulação certas idéias, implica mobilizar o interlocutor no sentido de levá-lo a aceitar determinados parâmetros, certos conceitos, o que constitui um direcionamento sobre a forma de pensar.

31 Pode-se dizer que entre o manual e a revista há traços de oposição, mas também uma forte aliança, uma grande afinidade ideológica impregnada de valores da sociedade capitalista neoliberal e de suas estratégias de gestão de pessoas e reestruturação produtiva. Esses discursos constroem a imagem de um trabalhador individualista, 
competitivo, obstinado e autocentrado. A competência consiste ainda em saber o que fazer com o corpo, em seguir comportamentos considerados adequados para padrões de um mundo flexível, volatilizado, no qual o trabalhador é visto a partir do desenvolvimento das suas potencialidades individuais (caráter, personalidade, atitudes). São modos de tentar legislar sobre o inusitado, o imprevisível, e que fazem com que a norma flutue entre a rigidez da regra e a fluidez de diretivas e recomendações.

\section{5. À guisa de conclusão}

Retomamos nossa pergunta inicial : em que medida a análise do discurso, associada aos princípios da ergologia, pode contribuir para o aumento das capacidades e das liberdades dos indivíduos? O percurso traçado mostra a possibilidade de uma tal expansão ao insistir na importância do domínio da leitura que leva em conta os princípios do "letramento discursivo". Esta forma de letramento busca proporcionar um espaço para expandir as capacidades de pesquisadores em ciências sociais e, consequentemente, de trabalhadores, de modo que possam participar de maneira mais crítica no desenvolvimento do seu entorno sócio-histórico, portanto, da sua atividade de trabalho.

\section{BIBLIOGRAFIA}

Amartya, S. (2000). Desenvolvimento Como Liberdade, Trad. Laura Teixeira Motta, São Paulo, Companhia Das Letras.

Bentolila, A. (1996). De L'illettrisme En General Et De L'école En Particulier, Paris, Plon.

Borim, R. A. (2006). Ethos Empresarial Na Prescrição Do Trabalho : Discursos Do Poder Em Manuais De Integração, Dissertação De Mestrado, Lael - Puc/Sp.

Geffroy, M-T. (2002). Lutter Contre L'illettrisme, Paris, La Documentation Française.

Kleiman, A. (1995). “ Modelos De Letramento E As Práticas De Alfabetização Na Escola », Em Kleiman, A. (Org) Os Significados Do Letramento : Uma Perspectiva Sobre A Prática Social Da Escrita, São Paulo, Mercado Das Letras.

Maingueneau, D. (1984). Genèses Du Discours, Paris : Pierre Mardaga.

Maingueneau, D. (2008). Gênese Dos Discursos, Trad. Sírio Possenti, São Paulo, Parábola.

Moirand, S ; Brasquet-Loubeyr, M. (1994). “Des Traces De Didatiticités », Em Les Medias : Faits Et Effets, Paris, Hachete, Pp. 20-33 (Le Français Dans Le Monde).

Nouroudine, A. (2002). “ A Linguagem : Dispositivo Revelador Da Complexidade Do Trabalho », Em Souza-E-Silva, M.C. \& Faïta, Daniel. (Org.) Linguagem E Trabalho : Construção De Objetos De Análise No Brasil E Na França, São Paulo, Cortez. 
Possenti, S. (2004). “ Teoria Do Discurso : Um Caso De Múltiplas Rupturas », Em Mussalin, F. \& Bentes, A.C. (Org.) Introdução A Lingüística : Fundamentos Epistemológicos, vol. 3, São Paulo, Cortez, Pp. 353-392.

Sant'anna, V. \& Souza-E-Silva, M. C. P. (2007). “Trabalho E Prescrição : Aproximações Ao Problema A Partir Dos Estudos Da Linguagem », Em Revista Matraga, N. 20, vol. 14, Pp. 77-99.

Schwartz, Y. (1997). Reconnaissances Du Travail, Pour Une Approche Ergologique, Paris, Puf.

Schwartz, Y.,Adriano, R. \& Abderrahmane, F. (2008). “ Revisitar A Actividade Humana Para Colocar As Questões Do Desenvolvimento : Projecto De Uma Sinergia Franco-Lusófona », Em Laboreal, vol. Iv, No. 1, Pp. 10-22. Disponível Em : Http://Laboreal.Up.Pt/Revista/Artigo.Php? Id $=48 u 560$ tv658223439657;8:3872.

Sennet, R. (2006). “ Les Failles Culturelles Du Nouveau Capitalisme », Em Sciences Humaines, N. 176, Pp. 38-39, Novembro 2006.

Soares, M. (2003) Letramento : Um Tema Em Três Gêneros, Belo Horizonte, Autêntica.

Sturm, I. (2006). As Relações Interdiscursivas Sobre O Trabalho Na Administração Moderna : A Prática Discursiva Da Você S/A, Tese De Doutorado, Iel - Unicamp.

\section{NOTAS}

1. Esses princípios resultam de debates sobre as contribuições da ergologia às problemáticas do desenvolvimento; tais debates ocorreram ao longo das II Jornadas da Rede Internacional Ergologia, Trabalho e Desenvolvimento (Belo Horizonte, Minas Gerais, novembro, 2009) e que orientaram nossa reflexão atual sobre as possíveis relações com os estudos da linguagem.

2. Essa análise, na íntegra, encontra-se em Sant'Anna \& Souza-e-Silva (2007).

3. Partes do manual foram trabalhadas, em um primeiro momento, por Borim (2006).

4. Sobre a Você S/A, em uma perspectiva mais ampla, consultar Sturm (2006).

5. Subconjuntos de posicionamentos discursivos que o analista, diante de seu propósito, julga relevante pôr em relação (MAINGUENEAU, 2008).

\section{RESUMOS}

Este artigo tem por objetivo articular a noção de desenvolvimento (Sen, 2000), o enfoque ergológico voltado para a atividade de trabalho (Schwartz, 1997, Schwartz, Adriano \& Abderrahmane, 2008) e os estudos da linguagem vistos sob a perspectiva discursiva (Mainguenau, 1984 ; Possenti, 2004). Tal articulação abre-se à idéia de um "letramento discursivo" capaz de proporcionar ao indivíduo um espaço de liberdade para aumentar suas "capabilidades" de compreensão do mundo e de participação mais crítica no desenvolvimento do seu entorno sóciohistórico.

Este articulo tiene como objetivo articular la noción de desarrollo (Sen, 2000), el enfoque ergológico vuelto hacia la actividad de trabajo (Schwartz, 1997, Schwartz, Adriano \& Abderrahmane, 2008) y los estudios del lenguaje según la perspectiva de los estudios discursivos 
(Maingueneau, 1984 ; Possenti, 2004). Esa articulación se abre a la idea de una "alfabetización discursiva" capaz de proporcionar al individuo un espacio de libertad para aumentar sus capacidades de comprensión del mundo y de participación más crítica en el desarrollo de su entorno sociohistórico.

Cet article a pour objectif d'articuler la notion de développement (Amartya Sen, 1999), la démarche ergologique orientée vers l'activité de travail (Schwartz, 1997, Schwartz, Adriano \& Abderrahmane, 2008) et les études de langage selon une perspective discursive (Maingueneau, 1984 ; Possenti, 2004). Une telle articulation s'ouvre à l'idée d'un “ littérisme discursif » de nature à procurer aux individus un espace de liberté pour élargir leurs “ capabilités » de compréhension du monde et une participation plus critique au développement de leur environnement sociohistorique.

This paper aims to link the notion of development (Sen, 2000), the ergological focus targeted at the work activity (Schwartz, 1997, Schwartz, Adriano \& Abderrahmane, 2008), and language studies as seen in the discourse perspective (Maingueneau, 1984, Possenti, 2004). Such links are open to the idea of a "discourse literacy" that is capable of providing the individual with a space of freedom to enhance his/her capability to understand the world and participate in a more critical way in the development of his/her social-historical surroundings.

\section{ÍNDICE}

Palabras claves: desarrollo, ergología, capabilidades, trabajo, alfabetización

Keywords: development, ergology, capability, work, discourse literacy

Palavras-chave: desenvolvimento, ergologia, capabilidades, trabalho, letramento discursivo

Mots-clés: développement, ergologie, capabilités, travail, littérisme discursif

\section{AUTORES}

\section{CECÍLIA SOUZA-E-SILVA}

Pontifícia Universidade Católica de São Paulo, Programa de Pós-graduação em Lingüística Aplicada aos Estudos da Linguagem, Rua Monte Alegre, 984, Perdizes, São Paulo, Brasil - CNPq ; cecilinh@uol.com.br

\section{VERA LUCIA SANT'ANNA}

Universidade do Estado do Rio de Janeiro - Pós-Graduação em Letras, Rua São Francisco Xavier 524, sala 11.029, bloco A, Maracanã, Rio de Janeiro, Brasil

verasantanna@terra.com.br 